\title{
Средний класс в фокусе экономического и социологического подходов: границы и внутренняя структура (на примере России) ${ }^{1}$
}

\author{
Н.Е. ТИХОНОВА*
}

\begin{abstract}
*Наталья Евгеньевна Тихонова - доктор социологических наук, главный научный сотрудник Центра стратификационных исследований, Институт социальной политики, Национальный исследовательский университет «Высшая школа экономики». Адрес: 101000, Москва, ул. Мясницкая, д. 20. E-mail: ntihonova@hse.ru

Цитирование: Тихонова Н.Е. (2020) Средний класс в фокусе экономического и социологического подходов: границы и внутренняя структура (на примере России) // Мир России. Т. 29. № 4. С. 34-56. DOI: 10.17323/1811-038X-2020-29-4-34-56
\end{abstract}

Основные подходы к изучению среднего класса - экономический и сочиологический - исходят из разных теоретических предпосылок и используются для решения различных исследовательских задач. Если экономический подход важен прежде всего для ичелей социальной политики, то сочиологический позволяет лучше понять сущцность определенного социума и характер его социальной структуры, выявить основные противоречия в развитии последней. Каждый из них существует во множестве вариантов, однако выделенный в рамках экономического подхода средний класс - это всегда средние по их благосостоянию или текущим доходам слои, включающие нижний средний и собственно средний класcы. В России понимаемылй таким образом средний класс составляет около двух третей населения. Выделенный в рамках сочииологического подхода средний класс, напротив, объединяет индивидов, занимающих срединные позиции в основных иерархиях сочиальных статусов, различающихся престижностью различных позиций в них. Ключевыми из них являются иерархии власти, собственности, текущих экономических возможностей/образа жизни и определяемого ими престижа. Как всякая сочиальная группа, средний класс характеризуется наличием в нем ядра и периферии этого ядра, но может быть структурирован и по слоям (в рамках вертикальной модели стратификации). В статье показано, что срединные позиции сразу во всех основных статусных иерархиях сейчас занимает сравнительно небольшая (около 8\%) часть массовых слоев российского общества. В силу консистентности их статусов можно говорить о них как о ядре среднего класса. Однако

1 Исследование осуществлено в рамках Программы фундаментальных исследований НИУ ВШЭ в 2020 г. 
более типичной для современной России является ситуаџия, когда эти позиции в больщей или меньшей степени не совпадают (неконсистентны). В этом случае важно понять, какие из групп с неконсистентными статусами могут быть отнесены к среднему классу и почему. Пример такого анализа, приведенный в статье, демонстрирует, что в России численность среднего класса составляет сейчас около $40 \%$ населения.

Ключевые слова: социальная стратификация, социальная структура, модель стратификации, средний класс, статусные позиции, статусы, консистентность статусов, рассогласованность статусов

В литературе, посвященной стратификационной тематике в современной России, вряд ли найдется проблема, вызывающая такой пристальный интерес, как средний класс. При этом оценки его численности колеблются весьма значительно, и, более того, некоторые авторы вообще считают преждевременным говорить о среднем классе как самостоятельном и массовом социальном субъекте применительно к российскому обществу. Это заставляет обратить особое внимание на теоретикометодологические проблемы его анализа, специфику подхода к нему в различных науках и вытекающие из этого особенности методик его выделения. Без четкого понимания того, когда и почему возникает средний класс, каковы его наиболее характерные особенности с точки зрения представителей разных наук и как в их рамках обычно строится его изучение, невозможно ни выработать критерии его выделения в ходе эмпирических исследований, ни оценить его численность и перспективы с учетом его различных трактовок. Разобраться в этих вопросах важно именно сейчас, поскольку особенности мирового экономического развития в последние десятилетия, а также начавшийся масштабный экономический кризис ведут к изменению состава среднего класса и вынуждают задуматься о сущности этого феномена.

\section{Эволюция среднего класса и его видения в экономической и социологической науках}

Первоначально термин «средний класс» использовался без строгого научного определения и подразумевал промежуточный слой, находящийся между «верхами» и «низами» общества. Именно так он трактовался и при анализе «третьего» сословия в Европе, выступившего прообразом массового среднего класса ${ }^{2}$. Реально же говорить о среднем классе как о самостоятельном и значимом социальном субъекте начали в США лишь применительно к ситуации XIX в., а в Европе несколькими десятилетиями позже. Его возникновение связывается обычно с переходом западных стран к индустриальному, а затем и позднеиндустриальному обществу, когда произошли усложнение технологий и расширение третичного сектора экономики, потребовавшие большого количества высококвалифицированных

2 От ситуации в Древней Греции и т. п. мы здесь отвлекаемся, хотя в работах некоторых древнегреческих авторов, например Аристотеля, действительно можно найти упоминания об этом специфическом социальном феномене. 
работников. Укрупнение производств и распространение акционерных обществ привели к массовизации такой категории работников, как менеджеры; развитие социальной инфраструктуры, систем образования и здравоохранения отразилось на росте численности врачей, учителей и т. п.

Увеличению численности среднего класса способствовала и социальная политика, проводимая практически всеми государствами на этапе позднеиндустриального развития. С 1930-х гг. в США («Новый курс» Рузвельта) и с 1950-х гг. в Западной Европе (возникновение государств всеобщего благосостояния) модель этой политики изменилась, а ее приоритеты сместились с борьбы с бедностью в сторону поддержки средних слоев. Во многом это обуславливалось сугубо прагматическими соображениями, поскольку именно средний класс обеспечивает экономику работниками с высококачественным человеческим капиталом, а также стимулирует общий рост экономики за счет широкого спроса на разнообразные товары и услуги.

Таким образом, возникновению массового среднего класса в так называемых развитых странах способствовали изменения в структуре и формах организации промышленного производства, развитие третичного сектора экономики и изменение модели социальной политики. Эти процессы привели к массовизации в социальной структуре общества позиций, которые находились и не внизу, и не наверху статусной иерархии.

Произошедшие трансформации самого среднего класса совпали по времени с изменениями в социальных науках. Его возникновение как массового социального субъекта пришлось на период становления социологии как самостоятельной отрасли знаний, а постепенное усложнение его структуры нашло отражение в росте внимания социологов к этим сюжетам. Если первоначально средний класс рассматривался ими как состоящий из двух относительно гомогенных подгрупп - «старого» и «нового» средних классов, то после привлекшей внимание к неоднородности «нового» среднего класса работы Ч. Миллса [Mills 1951] он стал восприниматься как состоящий из целого ряда весьма отличающихся друг от друга подгрупп. Соответственно, если с самого начала внимание привлекали его отличия от остальных классов общества, то затем в фокусе внимания оказалась его гетерогенность. И хотя идущая от экономического подхода традиция делать при анализе среднего класса акцент на уровне благосостояния (и прежде всего доходе) домохозяйства сохранилась, в т. ч. у части социологов, но в целом в рамках социологической традиции все большее внимание стало уделяться профессиональному статусу индивидов. Более того, в ряде случаев именно он начал рассматриваться социологами как наиболее важный индикатор принадлежности к среднему классу ${ }^{3}$ [Goldthorpe, McKnight 2003; Levine 1998 и др.]. Экономисты же, ориентированные сейчас прежде всего на анализ формирующегося за счет роста благосостояния населения развивающихся стран глобального (мирового) среднего класса с соответствующим изменением рынков различных товаров и услуг, сосредоточились в первую очередь на определении доходных границ этого глобального среднего класса (подробный обзор их подходов см. [Тихонова 2018, с. 10-48]).

\footnotetext{
3 Обратим внимание на то, что для первого (экономического) подхода наиболее типично рассмотрение в качестве объекта анализа домохозяйства, а для второго (социологического) - индивида.
} 
Впоследствии развитие процессов глобализации и начало перехода к постиндустриализму во многих странах Запада привели к преобразованию структуры экономики, а вслед за этим - и изменению положения различных профессиональных групп в составе среднего класса. Средние и нижние слои среднего класса, в отличие от его верхних сегментов, стали терять устойчивость своего положения, а переход к неолиберальной экономической и социальной политике с началом кризиса государств всеобщего благосостояния эти тенденции усилил. Под их влиянием ученые заговорили уже не просто о гетерогенности, но и о размывании и поляризации среднего класса, отражающих «распад индустриализма» [Wright, Dwyer 2003]. Однако эти процессы разворачивались на фоне по-прежнему растущей численности глобального среднего класса, что актуализировало также вопросы его внутренней структуры ${ }^{4}$.

Несколько иначе развивались события в нашей стране. В Советском Союзе средний класс интересовал в основном социологов, поскольку в условиях планового хозяйства и слабой дифференциации доходов изучение его с экономической точки зрения самостоятельного интереса не представляло. Однако ввиду господства в официальной идеологии пресловутой формулы «рабочий класс, колхозное крестьянство и интеллигенция» как определения структуры советского общества публикация основанных на альтернативных методологических подходах исследований по данной тематике стала возможна только к концу 1980-х гг. В этот момент численность среднего класса (понимавшегося тогда как средние по их благополучию слои, т. е. в соответствии с экономической трактовкой среднего класса) оценивалась разными авторами в диапазоне от 12-13 до 30\% - в зависимости от использовавшихся критериев [Наумова 1990; Стариков 1990]. С началом рыночных реформ и массовым обеднением населения в начале 1990-х гг. численность среднего класса резко сократилась, а кризис 1998 г. заставил некоторых ученых заговорить о его «смерти». Однако, несмотря на то, что средний класс действительно сильно пострадал от кризиса 1998 г., он и в 1999-2000 гг. продолжал существовать как массовый социальный субъект [Малева 2003; Горшков, Тихонова, Чепуренко 1999].

С показанной траекторией его эволюции в период 1980-1990-х гг. согласны практически все исследователи, занимающиеся проблематикой среднего класса в России ${ }^{5}$, хотя оценки его численности в разные периоды новейшей отечественной истории, как и использовавшиеся для его выделения критерии, заметно разнятся. При этом экономисты, в отличие от социологов, на протяжении всего этого периода оценивали средний класс как более массовую группу.

Что же касается дальнейшей судьбы среднего класса в России, то тут позиции разных исследователей расходятся. Так, Т.М. Малева, руководитель одной из наиболее авторитетных групп, работающих в этом направлении 6 , считает, что

\footnotetext{
4 Не останавливаясь подробно на истории становления среднего класса и анализе ее в литературе, отметим лишь, что подробный их обзор уже не раз давался как зарубежными, так и отечественными авторами [Archer, Blau 1993; Blumin 1989; Тихонова, Мареева 2009].

5 В числе авторов, в разное время активно работавших с этой проблематикой, - Е.М. Авраамова, Л.А. Беляева, Л.М. Григорьев, М.Э. Дмитриев, Т.И. Заславская, М. Кивинен, М.Д. Красильникова, Т.М. Малева, Л.Н. Овчарова, Л.А. Хахулина, О.И. Шкаратан и многие другие.

6 Самой известной работой данной группы является [Малева 2003].
} 
численность среднего класса, составлявшая в начале 2000 -х гг. около $20 \%$ населения, впоследствии оставалась практически неизменной [Малева, Бурдяк, Тындик 2015]. Так же оценивают долю среднего класса и Л.М. Григорьев с А.А. Салминой, отмечавшие, что «подъем <..> 1999-2007 гг. не изменил ни долю, ни положение среднего класса» [Григорьев, Салмина 2009, с. 9]. В то же время группа, работающая под руководством М.К. Горшкова, полагает, что в 2003-2008 гг. численность среднего класса выросла, в экономический кризис 2008-2009 гг. сократилась, к 2010 г. восстановилась, после чего «последовал новый этап его роста, при котором он “перешагнул" рубеж $40 \%$ и стабилизировался на этом уровне» [Горшков, Тихонова 2016, с. 337]. Причины расхождений социологов в оценках численности среднего класса в России, как и особенностей его эволюции, уже неоднократно становились и самостоятельным предметом анализа [Тихонова, Мареева 2009; Самсон, Красильникова 2010; Nikula, Chernysh 2020 и др.].

Однако масштаб этих расхождений сильно контрастирует с тем, как оценивают траекторию развития и численность среднего класса в 2010-х гг. в России экономисты, особенно проводящие кросс-национальные исследования. Они попрежнему считают российский средний класс гораздо более массовым, чем социологи: так, например, в публикациях Всемирного банка говорится, что средний класс, определяемый как доля населения, потребление которого на душу населения составляет не менее 10 долл. в день по паритету покупательной способности (ППС), с 1990-х гг. резко вырос и составил к 2014 г. в России около 60\% от общей численности населения [Доклад об экономике России 2014].

Столь разные мнения связаны с разницей того смысла, который вкладывается в понятие «средний класс» представителями различных наук и напрямую зависит от исследовательских задач экономистов и социологов. Особенности методологии применения экономического и социологического подходов к выделению среднего класса на примере ситуации в России и составляют основной предмет данной статьи.

Если же говорить не об общем подходе, а о его инструментализации на уровне методик, то экономисты выделяют средний класс (в случае использования критерия дохода) двумя основными способами. В первом из них, применяемом обычно для кросс-национальных исследований и изучения глобального среднего класса, используется абсолютный размер доходов (потому этот подход и называется абсолютным). При этом границы доходов среднего класса задаются, как правило, в диапазоне от 10 до 50 долл. по ППС [Доклад об экономике России 2014; Bhalla 2009; Milanovic, Yitzhaki 2002 и др.]. При всех плюсах такого метода (возможность международных сопоставлений, простота расчетов и т. п.) он имеет и ряд минусов. Во-первых, дискуссионна сама методика расчета паритета покупательной способности: даже крупные международные организации используют для этих целей существенно различающиеся методики. Во-вторых, дискуссионны границы в 10 и 50 долл., поскольку оба эти показателя - априорно заданные величины, в силу чего регулярно предпринимаются попытки использовать для выделения среднедоходных слоев, особенно в развивающихся странах, и другие доходные «пороги». Тем не менее для целей анализа глобального среднего класса метод, основанный на фиксировании определенных абсолютных его границ, является основным.

Второй подход, применяемый экономистами (а иногда и социологами) для выделения среднего класса, отталкивается от идеи о том, что он должен нахо- 
диться между низшим и высшим классами общества, а, следовательно, его доходы должны соответствовать срединным доходам населения той или иной страны. Методически это означает, что он выделяется относительно медианных для конкретного общества доходов, потому и называется относительным. Однако этот подход успешно работает только при двух условиях. Во-первых, используемый в его рамках срединный уровень доходов должен превышать «черту бедности» (прожиточный минимум) в конкретном обществе и позволять представителям среднего класса успешно решать в соответствии с существующими стандартами свои насущные материальные проблемы, включая обеспечение жильем, медицинской помощью и образованием (что воспринимается, отталкиваясь от опыта развитых стран, как сущностные особенности образа жизни среднего класса). Во-вторых, риски бедности для его представителей (т. е. вероятность для них оказаться в течение 3-5 лет в числе имеющих доходы ниже прожиточного минимума) не должны превышать 10\% [López-Calva, Ortiz-Juarez 2014]. Эти ограничения означают, что, хотя при относительном подходе средний класс рассматривается как группа людей со срединными для данного общества доходами, нижняя граница этих доходов может быть даже выше медианы в зависимости от уровня медианного дохода населения определенной страны.

Относительный метод предпочтителен, когда анализируется ситуация со средним классом в той или иной отдельно взятой стране. Он позволяет лучше оценить коррективы, необходимые в ее социальной политике для расширения данной группы. В рамках относительного подхода в качестве нижней и верхней границ среднего класса обычно используются «пороги», соответствующие 0,75 и $2^{7}$ медианам среднедушевых доходов в домохозяйстве [Birdsall, Graham, Pettinato 2000 и др.]. При этом в странах с сильным региональным или поселенческим неравенством доходов для выделения среднего класса в такой его трактовке в определенных локальных сообществах могут использоваться не страновые, а региональные или поселенческие медианы доходного распределения. В этом случае средний класс общества в целом рассматривается как совокупность средних классов соответствующих территориальных сообществ. Есть и исследования, также выполненные в рамках относительного подхода, где за основу выделения среднего класса принимаются квинтили (обычно 3 или 3-4) либо децили (3-9) доходного распределения, но более распространенным является все-таки отсчет от медианы.

Естественно, что этими подходами весь спектр методик, используемых экономистами для выделения среднего класса, не исчерпывается. Применяются также различные методы оценки не только текущих доходов, но и располагаемого имущества, или сочетание доходов и имущества. Средний класс может выделяться также с использованием черты бедности и коэффициента мультипликации, по доле расходов на продукты питания, по возможности удовлетворения своих базовых потребностей и т. д. (обзор этих подходов см. [Тихонова 2018; Тихонова, Мареева 2009]). Однако именно абсолютный и относительный подходы к выделению среднего класса на основе текущих доходов распространены в мире наиболее широко и активно используются, в т. ч. международными организациями [Under Pressure 2019]. И при абсолютном, и при относительном подходе средний

\footnotetext{
7 Отдельные исследователи понижают нижний порог его доходов до 0,7; 0,66 и даже 0,6 медианы или повышают верхний порог до 2,25 и выше [Atkinson, Brandolini 2013; Chauvel 2013].
} 
класс подразделяется обычно с точки зрения его структуры на нижний средний и собственно средний классы. Верхний средний класс - явление иного порядка и традиционно включается в состав высших классов.

Судя по результатам применения и абсолютного, и относительного подходов к выделению среднего класса в условиях России, его численность в России довольно велика. Так, если, опираясь на данные использованного нами массива данных $^{8}$, ориентироваться в качестве критерия принадлежности к среднему классу на диапазон среднедушевых ежедневных доходов в 10-50 долл. по ППС стоянию на начало 2019 г. в этот диапазон попадало почти 70\% россиян. При этом численность слоев, имеющих доходы ниже характерного для среднего класса по этой методике порога, составляла чуть более $20 \%$, а доля имеющих доходы менее 5 долл. по ППС практически совпала с долей бедных, рассчитываемой ФСГС РФ. Это подтверждает корректность данной методики в России для тех исследований, которые ориентированы на задачи социальной политики и в основе которых лежит оценка численности первоочередных получателей адресной социальной помощи. Однако в этом случае нижняя граница среднего класса оказывается ниже уровня официально принятого в России прожиточного минимума. Верхний же порог среднедушевых доходов в домохозяйствах среднего класса составлял при ее использовании в начале 2019 г. около 40000 руб. в месяц. Такая граница была более чем вдвое больше медианы доходного распределения по стране и доходы выше нее имели в начале 2019 г. менее 10\% россиян из массовых слоев населения, что, казалось бы, говорит об оправданности ее применения. Однако для ряда регионов России этот уровень доходов можно рассматривать скорее как средний, чем как высокий.

Таким образом, проблема определения границ доходов среднего класса в случае использования данной версии абсолютного подхода заключается, с одной стороны, в недоучете в нем особенностей России (для нижней границы - прежде всего ее климата, а для верхней - региональных различий стоимости жизни и очень глубокой дифференциации верхнего доходного дециля, в результате чего его нижние слои оказываются в нашей стране ближе к собственно среднему классу, чем к представителям Middle-up). Судя по всему, в России необходимо либо использовать более высокие пороги доходов среднего класса, чем 10 и 50 долл. по ППС, либо выделять средний класс с учетом ППС по регионам и затем агрегировать его на страновом уровне, что довольно сложно технически.

Что же касается среднего класса «по доходам», выделяемого в рамках относительного подхода, то в 2019 г. его численность составляла в России 55,5\%

\footnotetext{
8 Эмпирической базой нашего анализа послужил опрос, проведенный Левада-центром в январе 2019 г. по общероссийской выборке численностью 1626 респондентов, репрезентировавшей население страны от 18 лет и старше по федеральным округам, поселениям с разной численностью жителей и наличию законченного высшего образования. В выборку, которая носила многоступенчатый характер, вошли 15 городов с населением более 1 млн чел.; 15 городов с населением от 500 тыс. до 1 млн чел.; 31 город с населением от 100 до 500 тыс. чел.; 36 городских населенных пунктов с населением до 100 тыс. чел.; 40 сельских районов. Опрос проходил с отбором домохозяйств на заданном маршруте систематическим методом с фиксированным шагом. При отборе респондентов в домохозяйстве учитывались заданные по полу, возрасту и образованию квоты.

9 По данным Всемирного банка, в 2018 г. ППС составлял 26,88 руб. за доллар (PPP Conversion Factor, Private Consumption (LCU per International \$) - Russian Federation // The World Bank // https://data.worldbank.org/indicator/PA.NUS.PRVT.PP?locations=RU).
} 
при использовании поселенческой медианы доходов ${ }^{10}$ (если ориентироваться на диапазон 0,75-2 медианы) и 57,5\% при использовании страновой медианы. При этом доходы выделенной таким образом группы находились в диапазоне от 9375 до 53060 руб. при использовании поселенческой медианы и от 11250 руб. до 30000 руб. при использовании страновой медианы. С учетом тех представителей массовых слоев, среднедушевые ежемесячные доходы в домохозяйствах которых были выше двух медиан доходов, но не превышали при этом 100 долл. по ППС, предлагаемых некоторыми исследователями для развивающихся стран как верхняя граница доходов среднего класса [Kharas 2010], его доля в населении страны возрастала до 67,6\% при использовании поселенческой медианы и 61,0\% при использовании страновой медианы. Дополнительным аргументом в пользу включения членов данной группы в состав среднего выступала их принадлежность к доступным для социологических опросов массовым слоям населения, что в России нехарактерно для представителей высших слоев.

При социологическом подходе к анализу среднего класса методика его выделения гораздо сложнее, чем в рамках исследований экономистов. Это связано с тем, что в социологии под средним классом в явной или неявной форме подразумеваются индивиды, находящиеся в срединной статусной группе по совокупности их позиций в ключевых стратификационных иерархиях - либо только в иерархиях собственности и власти (в рамках неомарксистской традиции), либо также в иерархиях престижа и текущих экономических возможностей/образа жизни (в рамках неовеберианской традиции). При этом за основу методики выделения представителей среднего класса обычно принимается профессиональный статус человека. Именно он позволяет отделить собственников предприятий и самозанятых от наемных работников, что для обществ индустриального и позднеиндустриального типа важно также и для понимания специфики места человека в иерархии престижа. При этом наемные работники также существенно дифференцированы внутри себя по критериям власти и престижа: одни из них могут влиять на принятие решений в своей организации (хотя сами их не принимают), а другие нет. Еще одна форма их властного ресурса связана с тем, что часть из них имеет возможность определять те или иные характеристики своей трудовой деятельности (ее содержание, график работы и т. п.), а другие такой возможности не имеют. Все это смягчает эффекты отчуждения в труде и повышает субъективное благополучие человека, а соответственно - привлекательность и престижность соответствующей трудовой деятельности. Влияет наличие этих форм властного ресурса и на уровень доходов [Коленникова 2017].

Обычно различные формы властного ресурса, определяющие место в иерархии властных статусов, присущи людям, занимающимся сложными видами деятельности, предполагающими высокий уровень образования, который и сам по себе является престижным и повышает общий статус человека. Учет наличия высокого уровня образования и квалификации важен при социологическом подходе к среднему классу еще по одной причине. Как уже отмечалось выше, на место в общей статусной иерархии также влияет, наряду с престижностью места человека во властной иерархии и характера его трудовой деятельности в целом, объем находящейся

10 Использование поселенческой, а не страновой медианы определялось тем, что образ жизни и ее стоимость в городах разных типов и в сельской местности различаются довольно существенно, а Москва вообще занимает в этом отношении особое положение. 
в его распоряжении собственности. Однако в современном мире для широких слоев населения это уже не столько собственность в виде материальных или финансовых активов, сколько собственность в виде так называемых инкорпорированных видов капитала. Важнейший из них в условиях позднеиндустриальных и постиндустриальных обществ - человеческий капитал. Поэтому одно из основных отличий представителей среднего класса от находящихся в общественной иерархии ниже него слоев - наличие у его представителей такого уровня образования и квалификации, который не только престижен, но и способен приносить дополнительный по отношению к типичному для данного общества доход от трудовой деятельности. Рентоприносящим уровнем образования в нашей стране для всех профессиональных групп является только высшее образование [Лукьянова 2010; Tихонова, Каравай 2018]. Соответственно, наряду с профессиональным статусом для выделения представителей среднего класса в иерархиях власти и собственности обычно используется также критерий наличия рентоприносящего уровня образования.

Эти критерии тесно связаны друг с другом, поскольку определенный тип профессиональной деятельности обычно подразумевает и наличие соответствующего уровня образования. Однако в российских условиях такая связь прослеживается далеко не всегда [Гориков, Петухов 2017; Гориков, Тихонова 2016 и др.], и в нашей стране при выделении среднего класса обязательно необходимо учитывать оба критерия. Более того, поскольку в России и образование, и профессиональный статус оказываются менее жестко связаны с уровнем заработной платы индивидов, чем в развитых конкурентных экономиках, то при выделении среднего класса в ней необходимо учитывать и критерий дохода как своего рода дополнительный «фильтр».

Уже около 80 лет в социологии существует еще один подход к выделению среднего класса. Он описывает так называемый субъективный средний класс, т. е. тех, кто сам себя идентифицирует как его представителей [Хахулина 2008]. Этот подход важен для измерения уровней социально-психологического благополучия и потенциала социальной напряженности в обществе. Самоидентификация в его рамках обычно проводится на основе результатов либо вербальных тестов (самоотнесение себя к среднему классу в рамках предложенного для самоидентификации закрытого списка элементов социальной структуры), либо графических тестов, когда человек относит себя к срединным позициям в рамках графического изображения иерархии статусных позиций в обществе. Иногда критерий самоидентификации со средним классом включают также в многокритериальные методики его выделения [Малева 2003; Горшков, Тихонова 2016 и др.], хотя субъективный средний класс - явление принципиально иной природы, и такого рода смешение подходов скорее дополнительно запутывает ситуацию, чем проясняет ее.

\section{Срединные позиции в ключевых статусных иерархиях в современной России: методология эмпирического анализа}

Как было показано выше, экономический и социологический подходы к изучению среднего класса фиксируют два разных социальных феномена. При этом в обществах такого типа, как российское, экономический статус играет важную роль для определения места в интегральной статусной иерархии и при социо- 
логическом подходе к среднему классу не только потому, что уровень доходов в них менее жестко, чем в развитых странах, связан с профессиональным статусом, но и потому, что возможность вести определенный образ жизни входит, по мнению россиян, в число важнейших критериев статуса человека в обществе ${ }^{11}$ [Тихонова 2014, с. 65-66]. В этой связи необходимо уточнить, где проходит граница благополучия в современной России, т. е. какой уровень доходов отражает пребывание на срединных позициях в иерархии экономических статусов, определяющих и характерный для среднего класса образ жизни.

Решая эту задачу, мы отталкивались прежде всего от результатов большого исследования особенностей доходной стратификации современного российского общества, проведенного на массивах данных РМЭЗ НИУ ВШЭ 12 за несколько лет [Тихонова 2018]. В этом исследовании на основе анализа жизненных возможностей и рисков индивидов с разным уровнем доходов, образом и уровнем жизни, устойчивостью материального положения за несколько лет было показано, что в современной России границей относительного благополучия является уровень доходов, соответствующий примерно 1,25 медианы доходного распределения. В разные годы в соответствии с разными фазами экономического цикла эта граница может несколько колебаться в зависимости от того, какую именно медиану доходов брать за основу: страновую, региональную или поселенческую. Однако эти колебания в любом случае имеют незначительный характер. При этом группа, чьи доходы располагаются в диапазоне 0,75-1,25, находится выше черты бедности и также характеризуется определенными признаками благополучия, которое, однако, очень неустойчиво по своему характеру, и если для группы с доходами выше 1,25 медианы риски попадания в бедность на протяжении нескольких лет составляют менее $10 \%$, то для группы с доходами 0,75-1,25 медианы они в разы выше [Тихонова 2018, с. 93-148].

Для дополнительной проверки этих выводов и определения границы распространенности характерного для среднего класса образа жизни по состоянию на 2019 г. мы также выделили разные доходные группы: с доходами не более 0,75 поселенческой медианы, от 0,75 до 1,25 медианы и свыше 1,25 медианы. Поселенческая медиана была выбрана отчасти потому, что образ жизни в разных типах поселений дифференцируется в России в не меньшей степени, чем под влиянием разницы в доходах, а отчасти в силу сильных различий этого показателя в разных типах поселений. Так, медиана среднедушевых ежемесячных доходов в домохозяйстве составляла в нашем массиве: в Москве - 26530 руб., других городах с населением более 500 тыс. чел. - 15557 руб., городах с населением 100-500 тыс. чел. - 15000 руб., городах с населением менее 100 тыс. чел. 13333 руб. и в селах - 12500 руб.

Результаты проведенного нами анализа свидетельствуют, что в современной России в качестве границы доходов среднего класса действительно можно рассма-

\footnotetext{
11 Другими его критериями для россиян выступают место в иерархиях собственности (прежде всего уровень образования, поскольку сбережений и инвестиций, способных приносить сколько-нибудь ощутимый доход, как и своего бизнеса, подавляющее большинство россиян не имеет) и власти (должность).

12 Российский мониторинг экономического положения и здоровья населения НИУ ВШЭ (RLMS-HSE), проводимый Национальным исследовательским университетом «Высшая школа экономики» и ООО «Демоскоп» при участии Центра народонаселения Университета Северной Каролины и Института социологии ФНИСЦ РАН (http://www.hse.ru/rlms).
} 
тривать 1,25 медианы доходов, а не середину (медиану) доходного распределения или более низкий порог, поскольку только начиная с этого уровня:

- нормой становится оплата образовательных, оздоровительных и/или туристических услуг (три четверти группы с доходами от 1,25 медианы использовали их за последние 3 года при половине $(49,4-51,1 \%)$ в группах с доходами от 0,75 до 1,25 медианы и не более 0,75 медианы);

- платные медицинские услуги начинают использоваться безусловным большинством группы (61,9\% при том, что за последние 3 года в группах с доходами от 0,75 до 1,25 медианы и не более 0,75 медианы их использовали для кого-то из членов домохозяйства 54,1 и 49,8\% соответственно); при этом, что еще важнее, только при доходах более 1,25 медианы большинство использовавших эти услуги делает это из-за низкого качества бесплатных аналогов, а не из-за недоступности последних, как это происходит в группах с более низкими доходами;

- резко усиливается активность на рынке жилой недвижимости (приобрести или построить жилье удалось в последние 3 года 16,0\% представителей группы с доходами свыше 1,25 медиан и лишь 9,1\% членам группы с доходами 0,75-1,25 медианы); кроме того, жилища представителей данной группы примерно на 20\% просторнее, чем у группы с доходами 0,75-1,25 медианы, и практически всегда имеют все коммунальные удобства; жилищная ситуация в группе с доходами до 0,75 медианы при этом наихудшая;

- начинает доминировать $(62,1 \%)$ убежденность, что им несложно сводить концы с концами; в группах с более низкими доходами этой точки зрения придерживается безусловное меньшинство, то же относится и к ожиданиям на предстоящий год.

Все это свидетельствует о том, что россияне с доходами до 1,25 занимают в иерархии их текущего экономического статуса близкие между собой нижние позиции, группа с доходами от 1,25 медианы - средние, а не попадающие в социологические опросы элитные и субэлитные группы - верхние. Общая численность группы со среднедушевыми доходами свыше 1,25 поселенческой медианы составила в использованном массиве данных 32,8\% опрошенных. Еще около трети насчитывала группа с доходами 0,75-1,25 медианы, которая, хотя и входит в развитых странах в состав среднего класса, составляя в них так называемый нижний средний класс, в принципе не может рассматриваться в России, как было показано выше, в качестве составного элемента среднего класса.

Что же касается места в иерархии власти, то срединные позиции в ней в современном российском обществе могут быть определены применительно к массовым слоям населения только на основе анализа распространенности среди их представителей позиций, удовлетворяющих хотя бы одному из следующих условий: (1) они предполагают распоряжение ресурсами своей организации; (2) они дают возможность оказывать влияние на принятие решений, связанных с деятельностью организации; (3) занимающие их работники характеризуются хотя бы частичной автономностью труда. Позиций, удовлетворяющих всем трем этим условиям, в России сравнительно немного - около 10\% от всех рабочих мест. Два вида властного ресурса имеют $8,5 \%$ работающих россиян, а один $-40,6 \%$, причем в большинстве случаев это автономность труда, характерная для большинства руководителей, профессионалов и полупрофессионалов. У представителей рутинного нефизического труда его автономность характеризует уже менее половины группы, хотя 
в целом властный ресурс присутствует у большинства $(57,1 \%)$ ее представителей ${ }^{13}$. Такая форма властного ресурса, как ресурс влияния, присуща большинству лишь среди руководителей и профессионалов, а право принятия решений, относящихся к организации или ее подразделениям, - только руководителям.

В условиях, когда около 40\% работающего населения и многомиллионная масса неработающих россиян (в сумме свыше двух третей населения) вообще не имеют властного ресурса, наличие любой из его форм выгодно выделяет их обладателей и свидетельствует об их расположении на срединных позициях в иерархии властных статусов. С точки зрения типичности такого рода позиций для представителей различных профессиональных групп это означает принадлежность к занимающим срединные позиции в иерархии властных статусов прежде всего руководителей и профессионалов, а также, с определенной долей условности, полупрофессионалов и представителей рутинного нефизического труда (т. е. 1-4 классов по ISCO-08) ${ }^{14}$. Таким образом, и в российских условиях срединные позиции во властной иерархии характерны прежде всего для тех профессиональных групп «беловоротничковой» занятости, которые традиционно рассматриваются как база выделения среднего класса при социологическом подходе к нему на Западе. Хотя в нашей стране в составе этих групп есть довольно многочисленные подгруппы, позиции которых в иерархии властных статусов в силу специфики распределения властных полномочий в отечественной производственной культуре нельзя отнести к срединным, их представители характеризуются относительно высокими по сравнению с представителями других профессиональных классов статусными позициями в силу большей престижности «беловоротничковой» занятости.

К среднему классу по критерию профессионального статуса в нашем массиве данных могли быть отнесены 42,7\% опрошенных: из них 61,6\% составляли работающие, 28,3\% - неработающие пенсионеры с соответствующим профессиональным статусом в прошлом, а остальные 10,1\% - неработающие по другим причинам, также имевшие в прошлом соответствующий профессиональный статус.

Еще одним критерием для отнесения к среднему классу в его социологической трактовке является, как уже упоминалось выше, уровень образования, измеряемый либо числом лет обучения, либо (чаще) наличием диплома о законченном образовании определенной ступени. Этот критерий, как и профессиональный статус, также важен не сам по себе, а как свидетельство места в определенной статусной иерархии, в данном случае - иерархиях собственности и престижа. В числе рент на высшее образование есть не только монетарные, но и немонетарные, в т. ч. связанные с большей вероятностью обладания властным ресурсом, связь которого с уровнем образования прослеживается в современной России даже в рамках одних и тех же профессиональных групп. У профессионалов с высшим и с более низким уровнем образования, например, ресурс влияния на принятие решений на работе встречается

\footnotetext{
13 Проверка проводилась применительно к профессиональным классам, выделенным согласно классификатору International Standard Classification of Occupations (ISCO-08). Подробнее см.: [International Standard Classification of Occupations 2012].

14 Предприниматели, самозанятые и работающие в семейном бизнесе также в подавляющем большинстве относятся к среднему классу не только в силу наличия у них собственности в виде бизнеса, но и по своему властному статусу. Во всяком случае, те их представители, которые попадают в массовые опросы, примерно в $90 \%$ случаев (остальные в основном работают в семейном бизнесе, не имея никаких форм властного ресурса) могут быть отнесены к занимающим срединные позиции в иерархии власти.
} 
в 60,3 и $37,1 \%$ случаев соответственно. У квалифицированных рабочих с высшим образованием властный ресурс имеют 55,8\%, а без высшего образования - лишь $28,7 \%$. Более того, рабочие с высшим образованием в большинстве своем характеризуются также более высоким уровнем заработной платы, чем остальные рабочие. То же характерно и для других профессиональных групп. Все это говорит об оправданности для всех них, а не только для тех, где оно подразумевается должностными инструкциями, включения критерия образования при выделении среднего класса. По критерию наличия высшего образования в состав среднего класса в нашем массиве прошли $27,3 \%$ опрошенных: $67,7 \%$ из них составляли работающие, $18,6 \%$ - неработающие пенсионеры, а остальные $13,7 \%$ - не работающие по другим причинам.

Совмещение всех описанных критериев среднего класса (срединные позиции в иерархиях власти, собственности, текущих экономических возможностей/образа жизни и обусловленного ими престижа) дает картину, представленную на рисунке 1.

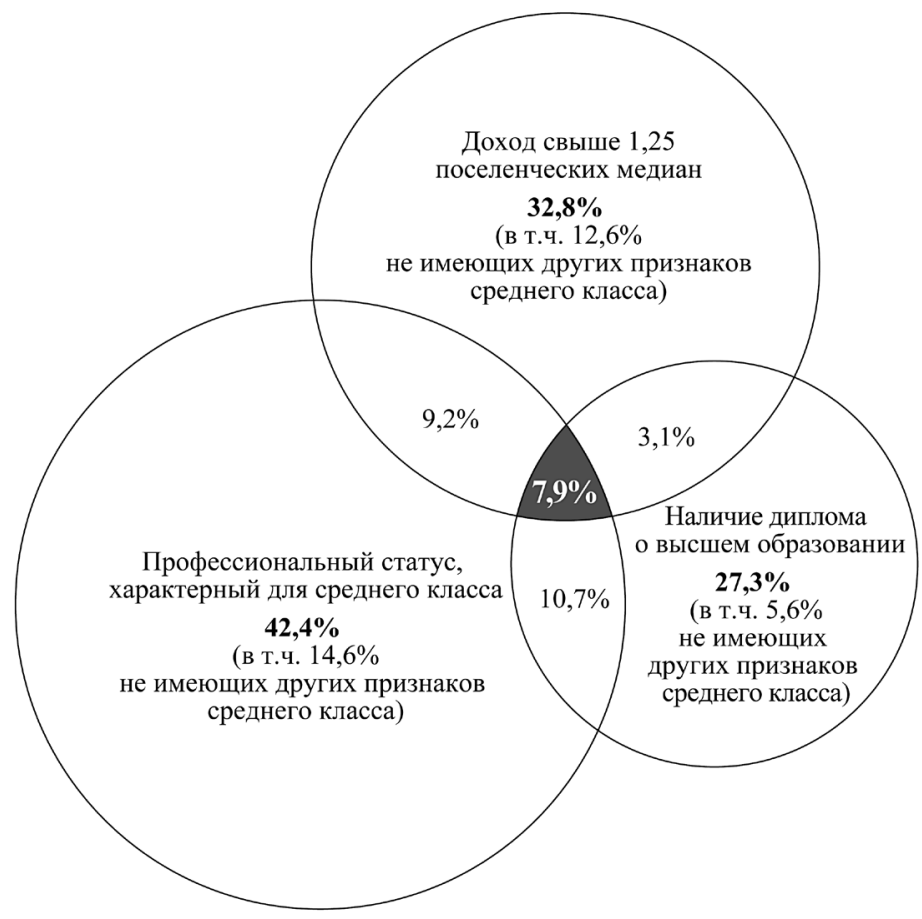

Рисунок 1. Доля групп с разным местом в иерархиях власти, собственности, текущих доходов и обусловленного ими престижа

в составе массовых слоев населения, \%

Одна из представленных на рисунке 1 групп, насчитывающая 7,9\% всех взрослых россиян, характеризуется срединными позициями сразу во всех рассматриваемых статусных иерархиях, и в этом смысле может быть отнесена не просто к среднему классу, но и к его ядру, для которой характерна консистентность (согласованность) позиций ее членов во всех ключевых статусных иерархиях. Столь же 
консистентны и позиции группы, не представленной на рисунке 1 , но являющейся самой многочисленной из всех рассматривавшихся в ходе исследования (36,7\%), которая одновременно находится на нижних позициях во всех статусных иерархиях, т. е. не имеет ни одного из учитывавшихся нами признаков среднего класса. Остальные группы характеризуются большей или меньшей неконсистентностью их статусов. В этой связи встает вопрос: какие из этих характеризующихся неконсистентностью статусов групп можно отнести к среднему классу, а какие нет, и где именно при всей ее неизбежной условности проходит граница между средним классом и остальными россиянами? Для получения ответов на эти вопросы мы провели проверку всех выделенных групп по ряду ключевых особенностей, обычно учитываемых при классовом анализе в его неовеберианской традиции. Сразу оговоримся, что полученные результаты - скорее иллюстрация применения на практике высказанных выше методологических соображений, чем попытка представить еще одну версию описания российского среднего класса.

\section{Характерные особенности различных подгрупп российского среднего класса}

Особенности использованного массива данных позволяли сравнить выделенные группы с разным местом в основных статусных иерархиях по таким показателям, как:

- наличие ключевых ресурсов (властного ресурса, человеческого и социального капитала, доходов и т. п.);

- уровень благосостояния и особенности потребления;

- устойчивость занятости и доходов в неблагоприятных внешних экономических условиях;

- социальная защищенность и особенности позиций на рынке труда;

- специфика социального воспроизводства и характер социальных связей;

- особенности статусной и классовой идентичностей.

Для упрощения этого сравнения при укрупнении представленных на рисунке 1 групп до пяти мы объединили тех, кто обладал либо способным приносить монетарные и немонетарные ренты уровнем образования, либо типичной для среднего класса «беловоротничковой» занятостью, в одну группу. Логика такого объединения основывалась на том, что «беловоротничковая» занятость и обладание вузовским дипломом чаще способны давать кумулятивный эффект в случае их одновременного присутствия. Так, заработную плату свыше 1,25 ее поселенческой медианы получали 29,3\% тех, кто имел либо типичный для среднего класса характер занятости, либо диплом о высшем образовании, в то время как в группе тех, у кого присутствовали оба эти признака, соответствующий показатель достигал 43,9\%. Доля тех, у кого на работе нарушались какие-либо базовые трудовые права (официальное оформление на работе, «белая» зарплата, оплата отпускных и больничных в полном объеме), составляла среди имевших либо типичный для среднего класса характер занятости, либо диплом о высшем образовании 28,6\%, в то время как в группе россиян, характеризовавшихся наличием обоих этих признаков, соответствующий показатель был более чем вдвое ниже (12,0\%) и т. п. Вторая группа, полученная по результатам этого укрупнения, отличалась от первой 
тем, что ее члены имели доход, позволяющий поддерживать присущий среднему классу образ и уровень жизни, хотя этот доход зачастую обеспечивался доходами других членов семьи.

В результате этого объединения общее число групп, которые сравнивались по ресурсам, благосостоянию, особенностям потребления, устойчивости занятости и т. д., сократилось с восьми до шести (шестой была группа, у которой отсутствовали все три признака среднего класса). Результаты сравнения этих шести групп частично представлены в таблице 1. По не вошедшим в нее характеристикам ответы распределились на основе тех же закономерностей. В итоге ядро среднего класса, как оказалось, обладало всеми рассматривавшимися особенностями; в группе с доходами от 1,25 медианы и либо типичным для представителей ядра среднего класса образованием, либо характерным для него профессиональным статусом этот показатель составлял уже $80 \%$; в группах с доходами не ниже 1,25 медианы или наличием одновременно высшего образования и типичного для среднего класса уровня доходов он был, соответственно, чуть ниже и чуть выше $60 \%$; большинство группы, имевшей только профессиональный статус либо образование, характерные для среднего класса, демонстрировало наличие только четверти из этих характеристик, а не имевшие ни одного признака среднего класса не обладали ни одной из них.

Основываясь на этих данных, можно утверждать, что в средний класс в современной России могут быть включены:

1) Лица со среднедушевыми доходами в домохозяйствах свыше 1,25 в их типах поселений, типичными для среднего класса профессиональными статусами и высшим образованием, составляющие ядро среднего класса $(7,9 \%$ взрослых россиян).

2) Лица со среднедушевыми доходами в домохозяйствах свыше 1,25 в их типах поселений, но с нетипичными для среднего класса профессиональными статусами или без высшего образования (ближняя периферия ядра среднего класса $-12,3 \%)$. В этой группе более половины имеют также властный ресурс в той или иной его форме, посему ее представители тоже занимают срединные позиции в большинстве статусных иерархий.

3) Те, кто обладает одновременно высшим образованием и профессиональными позициями, характерными для среднего класса, но чьи среднедушевые доходы ниже 1,25 медианы (при условии, что они выше уровня в 0,75 медианы доходов в их типах поселений, означающего в российских условиях уровень бедности). Данная группа (6,9\%) также занимает срединные позиции в большинстве статусных иерархий и является типичным средним классом с точки зрения процесса социального воспроизводства и даже уровня заработных плат работающих. Более низкий уровень среднедушевых доходов в ней связан обычно с нехарактерной для других подгрупп среднего класса иждивенческой нагрузкой ${ }^{15}$, что говорит о том, что зарплаты многих представителей российского среднего класса не предусматривают даже простого демографического воспроизводства ${ }^{16}$.

15 Более половины в данной группе, в отличие от других подгрупп среднего класса, составляют семьи с несовершеннолетними детьми.

16 При наличии даже одного несовершеннолетнего ребенка вероятность войти в состав ядра среднего класса снижается «при прочих равных» в полтора раза, а если детей двое, то сокращается почти в четыре раза. 
Таблица 1. Некоторые особенности групп, различающихся местом в иерархиях власти, собственности, доходов и обусловленного ими престижа ${ }^{17}$

\begin{tabular}{|c|c|c|c|c|c|c|}
\hline \multirow[b]{2}{*}{ Характеристики } & \multicolumn{6}{|c|}{ Группы с разной композицией признаков среднего класса (СК) } \\
\hline & $\begin{array}{c}\text { Ядро СК } \\
\text { (профес- } \\
\text { сиональ- } \\
\text { ный } \\
\text { статус, } \\
\text { образова- } \\
\text { ние, } \\
\text { доход) }\end{array}$ & $\begin{array}{l}\text { Профес- } \\
\text { сиональ- } \\
\text { ный ста- } \\
\text { тус или } \\
\text { образова- } \\
\text { ние СК } \\
\text { и доход } \\
\text { СК }\end{array}$ & $\begin{array}{l}\text { Толь- } \\
\text { ко до- } \\
\text { ход, } \\
\text { харак- } \\
\text { тер- } \\
\text { ный } \\
\text { для } \\
\text { СК }\end{array}$ & $\begin{array}{l}\text { Профес- } \\
\text { сио- } \\
\text { наль- } \\
\text { ный } \\
\text { статус и } \\
\text { образо- } \\
\text { вание } \\
\text { СК }\end{array}$ & $\begin{array}{l}\text { Про- } \\
\text { фессио- } \\
\text { наль- } \\
\text { ный ста- } \\
\text { тус или } \\
\text { образо- } \\
\text { вание } \\
\text { СК }\end{array}$ & $\begin{array}{c}\text { Не имеют } \\
\text { ни одного } \\
\text { признака } \\
\text { СК в его } \\
\text { социологи- } \\
\text { ческой или } \\
\text { экономичес- } \\
\text { кой трактовке }\end{array}$ \\
\hline \multicolumn{7}{|c|}{ Объективные характеристики } \\
\hline $\begin{array}{l}\text { Доля имеющих властный ресурс } \\
\text { в любой форме, \% от работающих } \\
\text { членов группы }\end{array}$ & 85,9 & 69,8 & 50,3 & 74,8 & 60,8 & 44,3 \\
\hline $\begin{array}{l}\text { Среднее число видов помощи, } \\
\text { которые могут оказать социальные } \\
\text { сети (в среднем по стране - } \\
1,73 \text { вида из } 10 \text { замерявшихся) }\end{array}$ & 2,35 & 1,89 & 1,96 & 1,96 & 1,73 & 1,40 \\
\hline $\begin{array}{l}\text { Медианная зарплата в группе } \\
\text { (при медианной зарплате по стране } \\
25000 \text { руб.), руб. }\end{array}$ & 40000 & 30000 & 25621 & 25000 & 20000 & 18000 \\
\hline $\begin{array}{l}\text { Среднедушевые доходы } \\
\text { в домохозяйствах (при средних } \\
\text { по стране } 18687 \text { руб.), руб. }\end{array}$ & 48839 & 33176 & 33287 & 15399 & 12570 & 11705 \\
\hline $\begin{array}{l}\text { Доля тех, чья номинальная зарплата } \\
\text { за период с весны } 2014 \text { г. до начала } \\
2019 \text { г. выросла, \% от работающих } \\
\text { членов группы }\end{array}$ & 56,6 & 56,2 & 45,5 & 43,9 & 38,0 & 36,0 \\
\hline $\begin{array}{l}\text { Хотя бы один из родителей был } \\
\text { руководителем, профессионалом } \\
\text { или полупрофессионалом, \% }\end{array}$ & 69,4 & 49,3 & 45,0 & 64,7 & 44,4 & 33,5 \\
\hline $\begin{array}{l}\text { За последние } 3 \text { года пользовались } \\
\text { платными образовательными, } \\
\text { рекреационными и туристическими } \\
\text { услугами, \% }\end{array}$ & 65,3 & 48,6 & 30,7 & 46,7 & 31,6 & 23,4 \\
\hline \multicolumn{7}{|c|}{ Субъективные характеристики } \\
\hline $\begin{array}{l}\text { Определяют себя } \\
\text { как представителя среднего } \\
\text { или нижнего среднего классов, \% }\end{array}$ & 91,0 & 69,8 & 51,6 & 77,2 & 52,1 & 41,5 \\
\hline $\begin{array}{l}\text { Самооценка собственного статуса } \\
\text { (при средней по стране в } 4,28 \text { балла } \\
\text { по 10-балльной шкале), баллы }\end{array}$ & 5,30 & 4,67 & 4,5 & 4,36 & 4,05 & 4,0 \\
\hline $\begin{array}{l}\text { Субъективное благополучие } \\
\text { (не считают сложным удовлетворять } \\
\text { основные потребности семьи), \% }\end{array}$ & 78,5 & 64,7 & 62,5 & 51,3 & 41,6 & 37,7 \\
\hline $\begin{array}{l}\text { Самооценка статуса родительской } \\
\text { семьи (при средней по стране в } 4,9 \\
\text { балла по 10-балльной шкале), баллы }\end{array}$ & 5,54 & 5,13 & 4,96 & 4,99 & 4,81 & 4,7 \\
\hline
\end{tabular}

17 Светло-серым фоном отмечено наличие соответствующих признаков более чем у 50\% членов группы или показателей, превышающих медианные/средние показатели по массиву. 
4) Обладатели высоких доходов, не входящие в характерные для представителей среднего класса профессиональные группы и не имеющие высшего образования (12,6\%), но, как уже отмечалось выше, все же относительно часто занимающие срединные позиции в иерархии престижа за счет их востребованности на рынке труда и отражающих ее сравнительно высоких зарплат.

В совокупности две последние группы, хотя и по разным причинам, составляют дальнюю периферию ядра среднего класса (19,5\%).

Определенный таким образом средний класс насчитывал по состоянию на начало 2019 г. 39,7\% населения страны: в его составе работающих было 72,1\%, пенсионеров - 18,2\%, не работающих по различным причинам (уход за детьми, плохое здоровье и т. п.) - 9,7\%. При этом, если использовать не концентрическую, а вертикально организованную слоевую модель структуры среднего класса, несколько упрощая, можно сказать, что верхние позиции в этой структуре займет ядро среднего класса, а нижний средний класс - это дальняя периферия ядра. Ближняя периферия ядра среднего класса входит в собственно средний (или «средний средний») класс.

В заключение подчеркнем, что граница между средним классом, остальными представителями массовых слоев населения (т. е. медианным классом, характеризующимся срединными позициями хотя бы в отдельных статусных иерархиях (23,6\%), и занимающим нижние позиции во всех них низшим классом $(36,7 \%))$ довольно условна. Кроме того, в зависимости от внешних экономических условий может меняться как число структурных позиций, которые можно отнести к среднему классу, так и индивидуальная принадлежность к нему. Наконец, с течением времени может изменяться и место конкретного индивида в структуре самого среднего класса. Однако принципиальное отличие его представителей во всех ключевых сферах жизни от остальных россиян прослеживается на эмпирических данных весьма четко.

\section{Выводы}

Средний класс, о котором говорят исследователи, - это всегда некий конструкт, являющийся продуктом деятельности того или иного ученого или группы ученых. Однако этот конструкт призван отражать объективную реальность, поскольку в иерархически структурированных обществах всегда были, есть и будут нижние, средние и верхние слои. То, какие основания выбирает исследователь для построения вертикально организованных социальных иерархий, зависит от его задач. Этим же обусловлена и его интерпретация понятия «средний класс». В любом случае никакое исследование не сможет зафиксировать средний класс абсолютно точно. Это связано как с исходными ограничениями процесса познания, так и с тем, что общество с его социальной структурой - непрерывно трансформирующийся объект, и средний класс в нем также постоянно изменяется. Однако общее представление о положении этой группы, а главное - о тенденциях ее изменения и проблемах в конкретном обществе, ее анализ дать способен.

Основные подходы при изучении среднего класса как реально существующего объекта можно объединить либо в экономический, либо в социологический. Их часто путают, а иногда механически совмещают, забывая, что они исходят из разных теоретических посылок и используются для решения различных целей. Выде- 
ленный в рамках экономического подхода средний класс - это фактически средние по их благосостоянию или текущим доходам слои, понимание ситуации в которых необходимо для оптимизации государственной политики. В России определяемый таким образом средний класс составляет около двух третей населения и делится внутри себя почти в равных долях на нижний средний и собственно средний классы.

Выделенный в рамках социологического подхода средний класс - более сложный феномен, объединяющий индивидов, которые занимают срединные позиции в большинстве ключевых статусных иерархий, включая иерархии власти, собственности, текущих экономических возможностей/образа жизни и определяемого ими престижа. Индивиды могут располагаться на срединных позициях сразу во всех этих иерархиях, и тогда мы говорим о консистентности их статусов. Но эти позиции могут и не совпадать, и тогда мы говорим об их неконсистентности. В этом случае возникают проблемы как микро- (к какому классу относится человек с неконсистентными статусами в разных иерархиях, за счет чего формируется неконсистентность его статусов в данный момент и т. п.), так и макроуровней (например, каковы последствия этой неконсистентности для общества в целом и экономики в частности).

Если экономический подход важен прежде всего для целей социальной политики, то социологический необходим для понимания сущности определенного социума, специфики распределения в нем власти и собственности (в т. ч. в невещественных и инкорпорированных ее формах), выявления дисбалансов между располагаемыми активами (прежде всего человеческим и культурным капиталом) и получаемыми на них рентами, выделения в социальной структуре общества социальных групп, принадлежность к которым обуславливает у их членов общие социальные действия и мировоззрение и т. д. Каждый из двух этих подходов существует в ряде методологических и методических вариантов. Выбор из них и их корректное применение предполагают учет не только задач исследования, но и основных особенностей того социума, в котором конкретный исследователь или группа ученых пытаются выявить средний класс.

С выбором и использованием методик выделения среднего класса в рамках экономического подхода особых теоретико-методологических вопросов обычно не возникает. И в мировой, и в отечественной научной литературе эта тема хорошо проработана, и вопрос выбора из этих методик определяется лишь задачами исследователя. Со средним классом в его социологической трактовке ситуация принципиально иная. В отечественной научной литературе почти нет работ, предметом которых были бы статусные иерархии, существующие в современном российском обществе (исключениями являются работы Н.Д. Коленниковой [Коленникова 2017] и С.Г. Саблиной [Саблина 2000]). Возможно, поэтому, выбирая критерии отнесения к среднему классу, российские социологи обычно никак не увязывают их со срединными позициями в статусных иерархиях, а просто интуитивно постулируют в качестве этих критериев какие-то признаки. Это приводит к снижению эвристического потенциала их исследований и невозможности плодотворной научной дискуссии о критериях принадлежности к среднему классу в современном российском обществе. Именно поэтому, если с «экономическим» средним классом в данной статье мы ограничились оценкой его численности в России, то с «социологическим» средним классом нам пришлось остановиться на методике его выделения более подробно.

Проведенный в статье анализ позволил нам обосновать определенные индикаторы нахождения на срединных позициях в различных статусных иерархиях. 
В частности, было установлено, что «беловоротничковый» характер занятости и в российских условиях выступает удачным индикатором места человека в иерархиях власти, собственности и престижа. Однако наиболее успешно он выполняет эту функцию при учете и критерия наличия законченного высшего образования, поскольку именно в совокупности определенные типы занятости и качество человеческого капитала приносят обычно композитные ренты монетарного и немонетарного характера. Именно поэтому даже при относительно невысоких среднедушевых доходах представители группы с «беловоротничковой» занятостью и высшим образованием характеризуются наличием большинства типичных для среднего класса черт, включая и относительно высокие зарплаты, что позволяет включать их в состав среднего класса, несмотря на уровень среднедушевых доходов в их домохозяйствах. Было установлено также, что наличие высшего образования даже среди рабочих обеспечивает большинству обладающих им не только более высокие доходы за счет рент на качество их человеческого капитала, но и наличие определенных форм властного ресурса, повышающих их шансы на занятие срединных позиций в иерархиях власти и престижа. Большие шансы на нахождение на срединных позициях в этих иерархиях предоставляет и «беловоротничковая» занятость. Однако в современном российском обществе изолированно друг от друга этот тип занятости и наличие высшего образования дают возможность включения в состав среднего класса только при сравнительно высоких (более 1,25 поселенческой медианы) среднедушевых доходах.

Применение этих критериев позволяет определить численность среднего класса в России по состоянию на 2019 г. примерно в 40\% от взрослого населения страны. Около половины его составляют представители собственно среднего класса (в рамках концепции концентрической структуры социальных групп являющиеся ядром всего среднего класса и ближней периферией этого ядра), а вторая его половина объединяет представителей нижнего среднего класса (дальнюю периферию его ядра).

Помимо этого, было продемонстрировано, что срединная (медианная) доходная группа не соответствует в нашей стране среднему классу в его социологическом смысле и что срединные позиции в различных статусных иерархиях в современной России, как правило, довольно слабо связаны между собой (неконсистентны). Лишь каждый пятый представитель среднего класса характеризуется консистентностью срединных статусов во всех ключевых статусных иерархиях. Такая рассогласованность статусных позиций свидетельствует о непрочности положения большинства представителей этого класса, заведомой размытости их классовых идентичностей и неизбежности распространенности среди них так называемой статусной фрустрации, ведущей к росту недовольства и социальной напряженности. Это означает, что базой для протестных настроений в стабильных экономических условиях в России будут выступать скорее периферийные слои среднего класса, чем малоимущее население. Более того, сравнительная малочисленность среднего класса и неконсистентность статусов большинства его членов свидетельствуют о том, что либо российское общество еще не достигло позднеиндустриального этапа развития, на котором средний класс составляет большинство населения (что противоречит структуре занятости в российской экономике), либо характерная для современной России система социально-экономических неравенств, «задающая» структуру позиций в модели стратификации общества, 
не соответствует этапу ее технологического развития. Такое имманентное современному российскому обществу противоречие уже в ближайшем будущем чревато значительными социальными трансформациями.

\section{Литература}

Горшков М.К., Петухов В.В. (ред.) (2017) Российское общество и вызовы времени. Книга пятая. М.: Весь Мир.

Горшков М.К., Тихонова Н.Е. (ред.) (2016) Средний класс в современной России. Опыт многолетних исследований. М.: Весь Мир.

Горшков М.К., Тихонова Н.Е., Чепуренко А.Ю. (ред.) (1999) Средний класс в современном российском обществе. М.: РОССПЭН.

Григорьев Л., Салмина А. (2009) Структура среднего класса в России: гипотезы и предварительный анализ // Российский средний класс: анализ структуры и финансового поведения. М.: ИНСОР, Экон-Информ. С. 5-100.

Доклад об экономике России 31: Кризис доверия обнажает слабость экономики (2014). М.: Всемирный банк. Представительство в России.

Коленникова Н.Д. (2017) Особенности властного статуса занятого населения современной России // Мониторинг общественного мнения. № 5(141). С. 214-232.

Лукьянова А.Л. (2010) Отдача от образования: что показывает мета-анализ // Экономический журнал Высшей школы экономики. Т. 14. № 3. С. 326-348.

Малева Т.М. (ред.) (2003) Средние классы в России: Экономические и социальные стратегии. М.: Гендальф.

Малева Т.М., Бурдяк А.Я., Тындик А.О. (2015) Средние классы на различных этапах жизненного пути // Журнал Новой экономической ассоциации. № 3(27). С. 109-138.

Наумова Н. (1990) Переходный период: Мировой опыт и наши проблемы // Коммунист. № 8. C. $3-14$.

Саблина С.Г. (2000) Кристаллизация статуса средних слоев в современной России // Социологический журнал. № 1-2. С. 100-111.

Самсон И., Красильникова М. (2010) Средний класс в России: зарождающаяся реальность или старый миф? // Вестник общественного мнения. Данные. Анализ. Дискуссии. № 4. С. 61-72.

Стариков Е. (1990) «Угрожает» ли нам появление «среднего класса»? // Знамя. № 10. C. $192-196$.

Тихонова Н.Е. (2014) Социальная структура России: теории и реальность. М. Новый хронограф.

Тихонова Н.Е. (ред.) (2018) Модель доходной стратификации российского общества: состояние, динамика, факторы. М.: Нестор-История.

Тихонова Н.Е., Каравай А.В. (2018) Динамика некоторых показателей общего человеческого капитала россиян в 2010-2015 гг. // Социологические исследования. № 5. С. 84-98.

Тихонова Н.Е., Мареева С.В. (2009) Средний класс: теория и реальность. М.: Альфа-М.

Хахулина Л.А. (2008) Субъективный средний класс: социологический анализ // Уровень жизни населения регионов России. № 11-12. С. 115-119.

Archer M., Blau J. (1993) Class Formation in Nineteenth-Century America: The Case of the Middle Class // Annual Review of Sociology, vol. 19, pp. 17-41.

Atkinson A.B., Brandolini A. (2013) On the Identification of the Middle Class // Income Inequality: Economic Disparities and the Middle Class in Affluent Countries (eds. Gornick J., Jäntti M.), Stanford, California: Stanford University Press, pp. 77-100.

Bhalla S. (2009) The Middle Class Kingdoms of India and China, Washington, DC: Peterson Institute for International Economics.

Birdsall N., Graham C., Pettinato S. (2000) Stuck in Tunnel: Is Globalization Muddling the Middle? // Center on Social and Economic Dynamics. Working Paper, vol. 14.

Blumin S.M. (1989) The Emergence of the Middle Class: Social Experience in the American City, 1760-1900, New York: Cambridge University Press. 
Chauvel L. (2013) Welfare Regimes, Cohorts and the Middle Classes // Income Inequality: Economic Disparities and the Middle Class in Affluent Countries (eds. Gornick J., Jäntti M.), Stanford, California: Stanford University Press, pp. 115-141.

Gilbert D., Kahl J. (1993) The American Class Structure (4th ed.), Belmont, CA: Wadsworth.

Goldthorpe J.H., McKnight A. (2003) The Economic Basis of Social Class // Sociology. Working Papers, University of Oxford.

International Standard Classification of Occupations: ISCO-08 (2012), Geneva: ILO.

Kharas H. (2010) The Emerging Middle Class in Developing Countries // OECD Development Centre. Working Paper, vol. 285.

Levine R. (1998) Social Class and Stratification: Classic Statements and Theoretical Debates, Lanham: Rowman \& Littlefield.

López-Calva L., Ortiz-Juarez E. (2014) A Vulnerability Approach to the Definition of the Middle Class // Journal of Economic Inequality, vol. 12, no 1, pp. 23-47.

Milanovic B., Yitzhaki S. (2002) Decomposing World Income Distribution: Does the World Have a Middle Class? // Review of Income and Wealth, vol. 48, no 2, pp. 155-178.

Mills C.W. (1951) White Collar. The American Middle Classes, New York.

Nikula J., Chernysh M.F. (eds.) (2020) Social Distinctions in Contemporary Russia: Waiting for the Middle-class Society? London: Routledge.

Under Pressure: The Squeezed Middle Class (2019), Paris: OECD Publishing. DOI: $10.1787 / 689$ afed1-en

Wright E.O., Dwyer R. (2003) The Patterns of Job Expansions in the USA: A Comparison of the 1960s and 1990s // Socio-Economic Review, vol. 1, no 3, pp. 289-325.

Wright E.O. (1997) Class Counts: Comparative Studies in Class Analysis, Cambridge: Cambridge University Press.

\title{
Various Theoretical Approaches to The Russian Middle Class: Thresholds and Internal Structure
}

\author{
N. TIKHONOVA*
}

\begin{abstract}
*Natalia Tikhonova - DSc in Sociology, Professor-researcher, Centre for Stratification Studies, Institute of Social Policy, National Research University Higher School of Economics. Address: 20 Myasnitskaya St., Moscow, 101000, Russian Federation. E-mail: ntihonova@hse.ru
\end{abstract}

Citation: Tikhonova N. (2020) Various Theoretical Approaches to The Russian Middle Class: Thresholds and Internal Structure. Mir Rossii, vol. 29, no 4, pp. 34-56 (in Russian). DOI: $10.17323 / 1811-038 X-2020-29-4-34-56$

\begin{abstract}
The main approaches to the study of the middle class can be put in two groups: economic and sociological. They are based on different theoretical assumptions and are used to solve different research problems. The economic approach is primarily important for the purposes of social policy, whereas the sociological one allows a better understanding of a particular society and its social structure, and the identification of the main
\end{abstract}


contradictions in its development. Each approach exists in many variations. Nevertheless, the middle class defined in the economic approach always comprises of the middle strata in terms of their welfare or current income, which are divided into the lower middle class and the upper middle class. In Russia, the middle class defined this way makes up about two-thirds of the population. The middle class defined in the framework of the sociological approach includes individuals who occupy middle positions in different status hierarchies; the key ones include power, property, economic opportunities, lifestyle, and prestige. Like any social group, the middle class consists of the core and the periphery but can also be structured into strata according to the vertical model of stratification. This article provides quantitative estimates of the segments of the Russian middle class. The core middle class, i.e. people simultaneously occupying middle positions in all of the status hierarchies comprise only a small part of the Russian population (less than $8 \%$ ). However, more typical for modern Russia is the situation when positions in different status hierarchies do not coincide. It is important to understand which groups with non-consistent statuses can be included in the middle class and why. The analysis presented in the article demonstrates that the middle class in Russia amounts to more than a third of the country's population.

Key words: social stratification, social structure, stratification models, the middle class, status positions, statuses, statuses consistency, status inconsistency

\section{References}

Archer M., Blau J. (1993) Class Formation in Nineteenth-Century America: The Case of the Middle Class. Annual Review of Sociology, vol. 19, pp. 17-41.

Atkinson A.B., Brandolini A. (2013) On the Identification of the Middle Class. Income Inequality: Economic Disparities and the Middle Class in Affluent Countries (eds. Gornick J., Jäntti M.), Stanford, California: Stanford University Press, pp. 77-100.

Bhalla S. (2009) The Middle Class Kingdoms of India and China, Washington, DC: Peterson Institute for International Economics.

Birdsall N., Graham C., Pettinato S. (2000) Stuck in Tunnel: Is Globalization Muddling the Middle? Center on Social and Economic Dynamics. Working Paper, vol. 14.

Blumin S.M. (1989) The Emergence of the Middle Class: Social Experience in the American City, 1760-1900, New York: Cambridge University Press.

Chauvel L. (2013) Welfare Regimes, Cohorts and the Middle Classes. Income Inequality: Economic Disparities and the Middle Class in Affluent Countries (eds. Gornick J., Jäntti M.), Stanford, California: Stanford University Press, pp. 115-141.

Doklad ob ekonomike Rossii 31: Krizis doveriya obnazhaet slabost' ekonomiki [Russian Economy Report 31: The Crisis of Confidence Reveals the Weakness of the Economy] (2014), Moscow: Vsemirnyj bank. Predstavitel'stvo v Rossii.

Gilbert D., Kahl J. (1993) The American Class Structure (4 ${ }^{\text {th }}$ ed.), Belmont, CA: Wadsworth.

Goldthorpe J.H., McKnight A. (2003) The Economic Basis of Social Class. Sociology. Working Papers, University of Oxford.

Gorshkov M.K., Petukhov V.V. (eds.) (2017) Rossijskoe obshchestvo i vyzovy vremeni. Kniga pyataya [Russian Society and the Challenges of the Time. Book Five], Moscow: Ves' Mir.

Gorshkov M.K., Tikhonova N.E. (eds.) (2016) Srednij klass v sovremennoj Rossii. Opyt mnogoletnikh issledovanij [The Middle Class in Modern Russia. The Experience of Many Years of Research], Moscow: Ves' Mir. 
Gorshkov M.K., Tikhonova N.E., Chepurenko A.Yu. (eds.) (1999) Srednij klass v sovremennom rossijskom obshchestve [The Middle Class in Modern Russian Society], Moscow: ROSSPEN.

Grigor'ev L., Salmina A. (2009) Struktura srednego klassa v Rossii: gipotezy i predvaritel'nyj analiz [The Structure of the Middle Class in Russia: Hypotheses and Preliminary Analysis]. Rossijskij srednij klass: analiz struktury i finansovogo povedeniya [Russian Middle Class: Analysis of the Structure and Financial Behavior], Moscow: INSOR, Ekon-Inform, pp. 5-100.

International Standard Classification of Occupations: ISCO-08 (2012), Geneva: ILO.

Khakhulina L.A. (2008) Sub'ektivnyj srednij klass: sotsiologicheskij analiz [Subjective Middle Class: a Sociological Analysis]. Uroven'zhizni naseleniya regionov Rossii, no 11-12, pp. 115-119.

Kharas H. (2010) The Emerging Middle Class in Developing Countries. OECD Development Centre. Working Paper, vol. 285.

Kolennikova N.D. (2017) Osobennosti vlastnogo statusa zanyatogo naseleniya sovremennoj Rossii [The Features of the Power Status of Employees in Modern Russia]. Monitoring of Public Opinion, no 5(141), pp. 214-232.

Levine R. (1998) Social Class and Stratification: Classic Statements and Theoretical Debates, Lanham: Rowman \& Littlefield.

López-Calva L., Ortiz-Juarez E. (2014) A Vulnerability Approach to the Definition of the Middle Class. Journal of Economic Inequality, vol. 12, no 1, pp. 23-47.

Luk'yanova A.L. (2010) Otdacha ot obrazovaniya: chto pokazyvaet meta-analiz [Returns to Education: a Meta-analysis]. The HSE Economic Journal, vol. 14, no 3, pp. 326-348.

Maleva T.M (ed.) (2003) Srednie klassy v Rossii: Ekonomicheskie i sotsial'nye strategii [Middle Classes in Russia: Economic and Social Strategies], Moscow: Gendal'f.

Maleva T.M., Burdyak A.Ya., Tyndik A.O. (2015) Srednie klassy na razlichnykh etapakh zhiznennogo puti [Middle Classes at Different Stages of Their Life]. The Journal of the New Economic Association, no 3(27), pp. 109-138.

Milanovic B., Yitzhaki S. (2002) Decomposing World Income Distribution: Does the World Have a Middle Class? Review of Income and Wealth, vol. 48, no 2, pp. 155-178.

Mills C.W. (1951) White Collar. The American Middle Classes, New York.

Naumova N. (1990) Perekhodnyj period: Mirovoj opyt i nashi problemy [The Transition Period: World Experience and Our Problems]. Kommunist, no 8, pp. 3-14.

Nikula J., Chernysh M.F. (eds.) (2020) Social Distinctions in Contemporary Russia: Waiting for the Middle-class Society? London: Routledge.

Sablina S.G. (2000) Kristallizatsiya statusa srednikh sloev v sovremennoj Rossii [The Crystallization Status of the Middle Strata in Modern Russia]. Sotsiologicheskij Zhurnal, no 1-2, pp. 100-111.

Samson I., Krasil'nikova M. (2010) Srednij klass v Rossii: zarozhdayushchayasya real'nost' ili staryj mif? [The Middle Class in Russia: An Emerging Reality or an Old Myth?]. Vestnik obshchestvennogo mneniya, no 4, pp. 61-72.

Starikov E. (1990) «Ugrozhaet» li nam poyavlenie «srednego klassa»? [Does "the Middle Class" Threaten Us?]. Znamya, no 10, pp. 192-196.

Tikhonova N.E. (2014) Sotsial'naya struktura Rossii: teorii i real'nost' [The Social Structure of Russia: Theory and Reality], Moscow: Novyj Khronograf.

Tikhonova N.E. (ed.) (2018) Model'dokhodnoj stratifikatsii rossijskogo obshchestva: sostoyanie, dinamika, faktory [Income Stratification Model of the Russian Society: State, Dynamics, Factors], Moscow: Nestor-Istoriya.

Tikhonova N.E., Karavaj A.V. (2018) Dinamika nekotorykh pokazatelej obshchego chelovecheskogo kapitala rossiyan v 2010-2015 gg. [The Dynamics of Some Indicators of the Total Human Capital of Russians in 2010-2015]. Sociological Studies, no 5, pp. 84-98.

Tikhonova N.E., Mareeva S.V. (2009) Srednij klass: teoriya i real'nost' [Middle Class: Theory and Reality], Moscow: Al'fa-M.

Under Pressure: The Squeezed Middle Class (2019), Paris: OECD Publishing. DOI: $10.1787 / 689$ afed1-en

Wright E.O., Dwyer R. (2003) The Patterns of Job Expansions in the USA: A Comparison of the 1960s and 1990s. Socio-Economic Review, vol. 1, no 3, pp. 289-325.

Wright E.O. (1997) Class Counts: Comparative Studies in Class Analysis, Cambridge: Cambridge University Press. 